\title{
Introduction
}

\section{L2 Writing in Non-English Languages: Toward a Fuller Understanding of L2 Writing}

\author{
Nur Yiğitoğlu and Melinda Reichelt
}

This book focuses on second language (L2) writing in non-English languages. Much of what we know about L2 writing is based on conclusions drawn from research on writing in the English language. However, as a great deal of L2 writing and writing instruction is undertaken in various languages other than English, it is necessary to look at L2 writing practices in non-English languages in order to have a more comprehensive understanding of $\mathrm{L} 2$ writing.

A review of the published work in the area reveals that $\mathrm{L} 2$ writing in non-English languages is underrepresented in the field, with very few works addressing the issues that learners of non-English languages face in their L2 writing development. Although limited in number, previous studies of L2 writing in non-English languages have provided some insights into different aspects of teaching and learning non-English languages. Some such studies focused on the specific needs of learners in non-English classrooms, such as Yiğitoğlu and Reichelt (2012), who discuss the teaching of Turkish language writing in the USA; and RuizFunes (2015), who investigates, in a Spanish class, specific pedagogical issues such as the interplay between $\mathrm{L} 2 /$ foreign language (FL) writing and attention to linguistic form, which is affected by task complexity. Additionally, Cimasko and Reichelt (2011) include not only chapters on English as a foreign language (EFL) writing, but also chapters on writing in FL French (Schultz, 2011), Japanese (Hatasa, 2011), Spanish (Lefkowitz, 2011; Nas \& van Esch, 2011) and German (Thorson, 2011).

Although these studies have contributed to our knowledge about non-English languages, given that non-English L2 writing is being taught in many different contexts, more attention should be given to various aspects of non-English L2 writing. However, the focus in L2 writing research and pedagogical literature remains, for the most part, on writing in L2 English. For example, Ferris and Hedgcock (2014), in their volume Teaching L2 Composition: Purpose, Process, and Practice, focus 
on L2 learners of English. In its first two editions (Ferris \& Hedgcock, 1998, 2005), the volume was titled Teaching ESL Composition: Purpose, Process, and Practice. However, the authors note in the preface to the 2014 edition that they have changed the book's title to include the broader term $L 2$ because '[n] ot all L2 writers are developing their skills in English'. They continue, 'we have accordingly changed references from "ESL" to "L2" (or in some cases we refer to student writers as "multilingual") throughout the book' (Ferris \& Hedgcock, 2014: xiv). While this acknowledgment of non-English L2 writers is welcome, the volume still focuses on L2 writers of English. For example, in describing various types of L2 writers, Ferris and Hedgcock include international students studying English in English-dominant contexts, students studying EFL outside English-dominant contexts, resident immigrants in English-speaking countries and Generation 1.5 students in English-speaking countries; they do not include L2 writers of languages other than English. Nonetheless, the volume provides a useful overview of issues related to English as a second language (ESL) writing, ones that can inform teaching and research in writing in non-English L2s. The authors describe the development of the field of ESL writing, noting that its parent disciplines are composition studies and applied linguistics. They provide readers with an overview of trends in first language (L1) and ESL composition pedagogy, describing product approaches, process approaches and the 'post-process era' (Ferris \& Hedgcock, 2014: 68). The authors also delineate relationships between reading and writing, discussing genre approaches to teaching ESL writing. Ferris and Hedgcock also discuss other salient issues in the field, including course design, instructional planning, response to student writing (including but not limited to error treatment) and classroom assessment of writing. The literature on L 2 writing has also provided us with an understanding of issues related to $\mathrm{L} 2$ writing such as academic knowledge (Hyland, 2009) and disciplinary discourses (Hyland, 2004a); genre (Hyland, 2004b); metadiscourse (Hyland, 2005); disciplinary identities (Hyland, 2012); and curricular issues in L2 writing (Hinkel, 2015), as well as issues related to vocabulary and grammar in L2 writers' texts (Hinkel, 2004). These works underline the complexity of academic writing in L2 writing and contribute to the understanding of L2 writing as a multifaceted process. As Hirvela et al. (2016: 59) argue, '...the recognition of the situated nature of learning, teaching and performing writing necessarily entails an equal recognition of the many purposes and values that writing may have for individuals and groups in diverse settings and communities of practice'.

Work that focuses primarily on ESL writing can provide important insights for scholarship related to non-English L2 writing, given the fact that writers of all L2s face some similar challenges. However, writers of non-English L2s also face distinct challenges, often stemming from the fact that they are writing in a range of contexts and are not writing 
in the world's most dominant language. Thus, in order to advance our understanding of L2 writing, to reach out to an international readership and to motivate scholars from various contexts to work on issues in writing in underrepresented languages, more scholarship on L2 writing in non-English languages is needed. The present edited collection highlights work on non-English L2 writing in languages and contexts that are underrepresented in the literature.

The goal of this edited collection is, then, to bring breadth to the field of L2 writing by including chapters on a broad range of languages and contexts. The volume covers different languages such as Basque, Chinese, French, Japanese, Korean, Polish and Spanish. It also covers several underrepresented contexts, including but not limited to L2 writing in primary education in Basque immersion schools, L2 Polish writing in Poland and Chinese students' L2 Korean writing in a Korean university setting. The chapters in the present collection explore various practices at different proficiency levels in teaching and learning to write in non-English languages in contexts such as an introductory-level Spanish writing course (Borrallo-Solís and Smith), an upper-level Spanish writing course (Seibert Hanson), an intermediate Spanish course (Valentín-Rivera) and an advanced Chinese writing course (Fang and Wang). Additionally, because writing as a pedagogical activity involves communication between instructors and students, non-English L2 writing studies in this volume also focus on these different agents: instructors (McKinley) and students (Mazzotta and Chiesa). Moreover, the volume focuses on various salient topics surrounding non-English L2 writing, including but not limited to heritage language learners (HLLs; Seibert Hanson, ValentínRivera), language revitalization in non-English L2 writing (Manterola), dominant ideologies surrounding non-English L2 writing (Song), challenges in teaching and learning non-English L2 writing (e.g. Rose) and innovative approaches to teaching non-English L2 writing (e.g. BorralloSolís and Smith; Allen and Paesani). Regarding research methodologies, the volume includes diverse modes of inquiry, including but not limited to pedagogical explorations (e.g. Rose), exploratory practices (e.g. Duperron), descriptive studies (e.g. Allen and Paesani; Borrallo-Solís and Smith; Rose and Gaze), mixed-method studies (e.g. Seibert Hanson), qualitative studies (e.g. Mazzotta and Chiesa; McKinley) and quantitative studies (e.g. Valentin-Rivíera).

\section{Overview of Chapters}

\section{Part 1: Curricular Issues}

This section includes chapters on writing in Spanish, Polish, French, Japanese and Chinese.

In the first chapter, Borrallo-Solís and Smith describe a universitylevel curriculum for an introductory Spanish FL writing course in the 
USA that focuses on writing through the senses. The course is designed to address students' negative perceptions of writing and their writing anxiety by fostering creativity, flexibility and interest. The course curriculum includes students creating written analyses of songs, descriptions of a favorite food, essays about a physical object that is significant to them, analyses of a picture or a photo and responses to and analyses of film.

In the next chapter, Dani Francuz Rose and Mateusz Gaze report on writing instruction in another under-researched L2, Polish. Their chapter outlines pedagogical practices for teaching academic writing in Polish as an L2 at a language school that prepares students for study at a Polish university. Rose and Gaze outline the types and topics for writing that are assigned, and the approaches taken to writing instruction in this context.

Allen and Paesani in the third chapter describe a literacy-based, advanced-level university French as an FL course in the USA. The course focuses on interpersonal communication during the reading and writing process as a means of motivating students, helping them better understand texts and preparing them to meet the expectations of their readers when they write. The curriculum includes four modules that address different authors and genres, including vignettes about cultural products or practices, ethnotexts and short stories. The course emphasizes individual and collaborative processes, with students working together to understand the content of the course through analysis of assigned reading, pre-writing, peer review, reflection on their own writing processes and reaction to their peers' texts. What is special about this curriculum is its focus on the development of a classroom reading and writing community.

McKinley focuses specifically on teaching rhetorical approaches in Japanese L2 writing by examining the L2 writing practices of four instructors of Japanese: two working in a university in Japan and two working in universities outside Japan. Data included the analysis of course descriptions and multiple interviews with the instructors. The analysis of several cases of university-level L2 writing instruction revealed some differences in teaching rhetorical approaches because of instructors' educational backgrounds.

Rose explores the challenges associated with learning Japanese as an L2 and an FL. The chapter first presents an overview of the Japanese language and presents L2 writing practices regarding teaching the Japanese writing system. Rose then illuminates some challenges of learning the Japanese writing systems and strategies for more efficient learning of Japanese writing. Rose concludes the chapter with some pedagogical implications such as sparking learners' cultural curiosity in the writing system and raising students' awareness regarding strategies that are salient to their own needs.

Fang and Wang describe written corrective feedback practices in an advanced Chinese language course in the USA. As they focused on teacher feedback and student revisions, the data came from the final essay 
writing task in the course. The feedback data analysis indicated a strong focus on error treatment, predominantly direct feedback, especially on grammar-related errors. Overall, the students' revisions were successful but despite the direct feedback provided to them, students did not always simply take the correct form supplied by the teacher; instead, they made revisions that made sense to them.

\section{Part 2: Multiple Languages in Contact/ Conflict in L2 Writing Instruction}

This section includes chapters on writing in Basque, French and Korean.

Ibon Manterola reports on a study of recipes written by 11-year-old students of Basque. Students came from Spanish-speaking homes and were enrolled in an L2 Basque immersion program in the Basque region of Spain. Students were asked to write recipes in Basque for a popular Basque sandwich, to be read by recently arrived 11-year-old immigrants from Romania and Bulgaria. The resulting recipes were analyzed for adherence to genre requirements as well as the presence of appropriate text organizers, with an eye toward evaluating the potential of recipe-writing toward the pedagogical goals of language revitalization in this context.

Duperron's chapter also focuses on writing in French as an L2, both as an L2 and an FL. She reports on the L2 French writing development of university students studying at their home institution in the USA as well as at a study abroad location in France. Her research focuses on the multilingual writing center at the US-based institution as well as a writing center at the study abroad university. Through observations and interviews with students, tutors and an instructor, Duperron investigates the writing development of the study abroad participants, focusing on their perceptions of their move from the FL French classroom in the USA to their study abroad site in France.

The chapter by Juyoung Song explores the teaching and learning of writing in Korean as a second language (KSL) in South Korea (hereafter Korea), focusing on how language ideology and policy in a given context affect the learning of writing in KSL. Data included a survey of 154 KSL learners and interviews with 16 learners and teachers. The results indicated that various contextual factors affect learning and teaching KSL writing. For example, while students have positive attitudes toward the value of KSL writing, learners consider English writing and Korean speaking skills more important to their academic and future career than KSL writing. Similarly, while teachers expressed their perceptions with regard to the goal of the Korean language program to help students gain an ability to communicate rather than academic language proficiency, the program curriculum documents overall do not put much emphasis on Korean communication in writing. 


\section{Part 3: Affect and Student Attitudes Toward Pedagogical Practices}

This section includes chapters on writing in Japanese and Spanish.

In their chapters, both Valentín-Rivera and Seibert Hanson report on FL learners and HLLs of Spanish in US university classes. ValentínRivera investigates the effect of direct and indirect corrective feedback on the roles played by intermediate Spanish FL learners and HLLs when they wrote three narratives together. She examines whether the type of corrective feedback students received impacted the roles that writers played in their collaborative efforts, and whether the roles they played changed over time. Valentín-Rivera also examines how the writers perceived paired writing and whether their writing performance correlated with their attitudes about collaborative writing.

Seibert Hanson compares the motivation of Spanish FL learners and HLLs regarding learning to write in Spanish through analyzing student responses to questionnaires about motivation and through examining student freewriting about relevant personal experiences. Seibert Hanson compares the extrinsic motivation of HLLs with that of FL learners, examining change over time, and also compares the extrinsic motivation for writing of Spanish majors and non-majors, also investigating change over time. Additionally, Seibert Hanson explores ways of improving all students' intrinsic motivation for writing.

Mizuki Mazzotta and David L. Chisea looked at the role of learner affect in L2 Japanese writing tutorials. The chapter presents a case study of two American Japanese as a foreign language (JFL) learners to explore the impact of dialogic corrective feedback in writing on L2 Japanese learning by looking at changes in grammatical accuracy and the learners' affective responses. Data included oral data sources from interviews and tutoring sessions as well as written documents from different drafts of participants' writings, field notes, transcripts of interviews and stimulated recall sessions. Results revealed that affect plays a significant role in the $\mathrm{L} 2$ writing feedback process and thus it affords an optimal opportunity for the teacher/tutor to motivate the learners to continue studying Japanese.

Because of the dominant role that English plays as a world language, writing in L2s other than English has received less attention. We hope that this collection of chapters will not only move beyond the research conducted in L2 writing in English, but also make non-English L2 writing more visible by drawing specific attention to global contexts and emphasizing under-researched areas of non-English L2 writing.

\section{References}

Cimasko, T. and Reichelt, M. (eds) (2011) Foreign Language Writing Instruction: Principles and Practices. Anderson, SC: Parlor Press. 
Ferris, D. and Hedgcock, J. (1998) Teaching ESL Composition: Purpose, Process, and Practice. Mahwah, NJ/London: Lawrence Erlbaum.

Ferris, D. and Hedgcock, J. (2005) Teaching ESL Composition: Purpose, Process, and Practice (2nd edn). Mahwah, NJ/London: Lawrence Erlbaum.

Ferris, D. and Hedgcock, J. (2014) Teaching L2 Composition: Purpose, Process, and Practice (3rd edn). New York/London: Routledge.

Hatasa, Y.A. (2011) L2 writing instruction in Japanese. In T. Cimasko and M. Reichelt (eds) Foreign Language Writing Instruction: Principles and Practices (pp. 98-117). Anderson, SC: Parlor Press.

Hinkel, E. (2004) Teaching Academic ESL Writing: Practical Techniques in Vocabulary and Grammar. New York/London: Routledge.

Hinkel, E. (2015) Effective Curriculum for Teaching L2 Writing: Principles and Techniques. New York/London: Routledge.

Hirvela, A., Hyland, K. and Manchón, R. (2016) Dimensions in L2 writing theory and research. In R.M. Manchón and P.K. Matsuda (eds) Handbook of Second and Foreign Language Writing (pp. 45-64). Boston, MA/Berlin: DeGruyter.

Hyland, K. (2004a) Disciplinary Discourses: Social Interactions in Academic Writing. Ann Arbor, MI: University of Michigan Press.

Hyland, K. (2004b) Genre and Second Language Writing. Ann Arbor, MI: University of Michigan Press.

Hyland, K. (2005) Metadiscourse. London: Continuum.

Hyland, K. (2009) Academic Discourse. London: Continuum.

Hyland, K. (2012) Disciplinary Identities. Cambridge: Cambridge University Press.

Lefkowitz, N. (2011) The quest for grammatical accuracy: Writing instruction among foreign and heritage language educators. In T. Cimasko and M. Reichelt (eds) Foreign Language Writing Instruction: Principles and Practices (pp. 225-254). Anderson, SC: Parlor Press.

Nas, M. and van Esch, K. (2011) Developing Spanish FL writing skills at a Netherlands university: In search of balance. In T. Cimasko and M. Reichelt (eds) Foreign Language Writing Instruction: Principles and Practices (pp. 201-224). Anderson, SC: Parlor Press.

Ruiz-Funes, M. (2015) Exploring the potential of second/foreign language writing for language learning: The effects of task factors and learner variables. Journal of Second Language Writing 28, 1-19.

Schultz, J.M. (2011) Foreign language writing in the era of globalization. In T. Cimasko and M. Reichelt (eds) Foreign Language Writing Instruction: Principles and Practices (pp. 65-82). Anderson, SC: Parlor Press.

Thorson, H. (2011) Student perceptions of writing as a tool for increasing oral proficiency in German. In T. Cimasko and M. Reichelt (eds) Foreign Language Writing Instruction: Principles and Practices (pp. 255-284). Anderson, SC: Parlor Press.

Yiğitoğlu, N. and Reichelt, M. (2012) Teaching Turkish and Turkish-language writing in the U.S.: A descriptive report. Journal of Second Language Writing 21 (1), 71-75. 
